\title{
Optimal Power Flow Using Flower Pollination Algorithm: A Case Study of 500 kV Java-Bali Power System
}

\author{
Fredi Prima Sakti ${ }^{1}$, Sarjiya ${ }^{2}$, Sasongko Pramono Hadi ${ }^{3}$
}

\begin{abstract}
Flower Pollination Algorithm (FPA) is one of metaheuristic methods that is widely used in optimization problems. This method was inspired by the nature of flower pollination. In this research, FPA is applied to solve Optimal Power Flow (OPF) problems with case study of $500 \mathrm{kV}$ Java-Bali power system in Indonesia. The system consists of 25 bus with 30 lines and 8 generating units. Control variables are generation of active power and voltage magnitude at $\mathrm{PV}$ bus and swing bus under several power system constraints. The results show that FPA method is capable of solving OPF problem. This method decreased the generator fuel cost of PT. PLN (Persero), the stateowned company in charge of providing electricity in Indonesia, up to $13.15 \%$.
\end{abstract}

Keyword-Optimal power flow, flower pollination algorithm, Java-Bali $500 \mathrm{kV}$ system, voltage magnitude, capacity of the transmission line.

\section{INTRODUCTION}

The total capacity of power plants should be greater than the total electrical load demand so that the electrical energy supply can be adequate. The total installed capacity of power plants in Indonesia reaches 40,265.62 MW, 27,867.88 MW (69.21\%) of which are located in the Java Island. When classified by the types of units, steam turbine and combined cycle have the biggest proportion with $53.90 \%$ and $28.33 \%$ respectively. Hydro plants make up to $8.63 \%$, while gas turbine $7.10 \%$, geothermal $1.24 \%$ and diesel $0.80 \%$ [1]. Thermal power plants, especially steam turbines and combined cycle, are dominating the composition of installed power plants in Java Island. Thermal power plants are the power plants that convert heat energy from fuel combustion to get the mechanical energy used to drive the turbine and then generates electrical energy. This causes fuel to be an integral part of thermal power plants.

Fuel cost and lubricants have a dominant contribution in the composition of the operations cost. According to statistical reports of PT. PLN (Persero) in 2015 [1], the amount of total electricity operating cost is Rp246 trillion, which consists of power purchasing and diesel rent costs, fuel and lubricating oil, maintenance, staffing, depreciation of fixed assets, and other costs. The cost of power purchasing and diesel rent reached Rp59.3 trillion (24.08\%), the cost of fuel and

\footnotetext{
${ }^{1}$ Student, Department of Electrical Engineering \& Information Technology, Universitas Gadjah Mada, Jl. Grafika 2 Yogyakarta 55281 INDONESIA (tlp: 0274-555 225; e-mail: fredipsakti@gmail.com)

${ }^{2,3}$ Lecturer, Department of Electrical Engineering \& Information Technology, Universitas Gadjah Mada, e-mail: sarjiya@ugm.ac.id, sasongko@te.ugm.ac.id)
}

lubricants Rp120.6 trillion (49.02\%), maintenance costs Rp17.6 trillion (7.15\%), staffing costs reached Rp20.3 trillion (8.26\%), the cost of depreciation of fixed assets Rp21.4 trillion (8.71\%), while other expenses reached Rp6.8 trillion $(2.78 \%)$. Based on the data, it can be seen that the cost of fuel and lubricant oil makes up the majority of total electricity operating costs.

One solution to minimize the operational costs of electric power systems is to optimize the cost of the electrical energy production process. In an interconnection system, one way to minimize fuel cost is done by optimizing the generation of active and reactive power in each plant. This method is called optimal power flow (OPF) [2]. The idea of optimal power flow (OPF) is introduced in early 1960s. It has been developed from economic dispatch that is used to determine the optimal setting of control variables while concerning various constraints. The optimal power flow is an important problem of power systems in which certain control variables are adjusted to minimize an objective function such as the cost of active power generation or the losses, while satisfying physical and operating limits on various controls, dependent variables and function of variables.

One of the techniques to solve the OPF problem is by using the metaheuristic optimization methods. The use of metaheuristic methods has been widely used to solve OPF problems, such as Evolutionary Programming (EP) [3], Differential Evolution (DE) [4], Particle Swarm Optimization (PSO) [5], Genetic Algorithm (GA) [6] and Flower Pollination Algorithm (FPA) [7] - [10].

The use of FPA methods to solve OPF problems has been done by previous researchers [7] - [10]. Researchers use Flexible AC Transmission System (FACTS) to get minimum line power losses and fuel costs with active power generator as control variables [7]. In other studies [8], Thyristor Controlled Series Capacitor (TCSC) is used as a control variable of OPF problems with the objective function of minimizing line power losses. Valve point effect of generator are taken into account in other studies [9] whose objective function is to get the minimal fuel costs. Furthermore, the addition of Static VAR Compensator (SVC) as a control variable and the addition of the influence of valve-point loading effect on the fuel function is shown in other studies [10].

In this study, the FPA method is applied to solve the OPF problem in the $500 \mathrm{kV}$ electrical system of Java-Bali in Indonesia. This research is conducted to obtain minimum fuel costs with active power and voltage magnitude as control variables. 


\section{OPtimal POWER FLOW FORMULATION}

As mentioned in the previous section, fuel cost contributes to almost half of the total operations cost of PT. PLN (Persero). Therefore, this research will formulate the minimization of fuel costs by optimizing active power generation of power plant. The fuel cost function of each plant is described as a second-order quadratic curve. Generally the function is described as:

$$
\mathrm{f}\left(\mathrm{P}_{\mathrm{G}}\right)=\sum_{i=1}^{N_{g}}\left(\alpha_{i}+\beta_{i} P_{G i}+\gamma_{i} P_{G i}^{2}\right)
$$

where $\mathrm{Ng}$ represents the total number of existing plants in the system including the generators on the slack bus. $P_{G i}$ is an active power generation by the $i$-th power plant, while $\alpha_{i}, \beta_{i}, \gamma_{i}$ are the coefficient of fuel function in the $i$-th power plant.

\section{A. Control Variable}

The control variable is a variable whose values can be modified to get the minimum value of the objective function. Control variable in this research are active power at PV bus except slack bus and magnitude voltage at PV bus include slack bus.

\section{B. Objective Function Constraint}

OPF utilizes a number of both equality and inequality constraints as shown below.

1) Equality Constraint: When minimizing fuel costs, it must be ensured that the amount of generated power equals the total of load demand coupled to power losses in the lines.

$$
\begin{aligned}
& P_{G i}-P_{D i}-\sum_{j=1}^{n_{b}} V_{i} V_{j}\left(g_{i j} \cos \theta_{i j}+b_{i j} \sin \theta_{i j}\right)=0 \\
& Q_{G i}-Q_{D i}-\sum_{j=1}^{n_{b}} V_{i} V_{j}\left(g_{i j} \sin \theta_{i j}+b_{i j} \cos \theta_{i j}\right)=0
\end{aligned}
$$

where,

$\mathrm{P}_{\mathrm{Gi}}$ : Total active power generated by the generator at bus-i.

$\mathrm{P}_{\mathrm{Di}}$ : Total active power load at bus-i.

$\mathrm{Q}_{\mathrm{Gi}}$ : Total reactive power generated by generator on bus-i.

$\mathrm{Q}_{\mathrm{Di}}$ : Total reactive power load on bus-i.

$\mathrm{V}_{\mathrm{i}}$ : Voltage magnitude on bus-i.

$\mathrm{V}_{\mathrm{j}}$ : Voltage magnitude on bus-j.

$\mathrm{g}_{\mathrm{ij}}$ : Real-part of the matrix called the admittance or conductance.

$b_{\mathrm{ij}}$ : The imaginary part of the referred to susceptance.

$\theta_{\mathrm{ij}}$ : Voltage angel element to $\mathrm{ij}$ of the admittance matrix.

nb : Bus number on the system.

2) Inequality Constraints: The inequality constraints are bounded by an upper and lower limit. Constraints are used to maintain the security of the system.

- Generator Constraint.

Active and reactive power of all generators must not exceed the upper and lower limit. Constraint were applied to all generators, including generators on the slack bus.

$$
\begin{gathered}
P_{G i}^{\min } \leq P_{G i} \leq P_{G i}^{\max }, i=1, \ldots \ldots, N g \\
Q_{G i}^{\min } \leq Q_{G i} \leq Q_{G i}^{\max }, i=1, \ldots \ldots, N g
\end{gathered}
$$

where $\mathrm{Ng}$ is the number of generator buses.

- Constraints of Voltage Magnitudes.

The voltage magnitude is required to be within the range that is permitted by the relevant authorities. These values must be maintained to guarantee the quality of the electric power system.

$$
V_{i}^{\min } \leq V_{i} \leq V_{i}^{\max }, i=1, \ldots \ldots, \text { Nbus }
$$

where Nbus is the number of buses including load bus, generator bus and swing bus.

- Power Flow Line Constraint

Power flow line constraint is used to limit the current passing through each branch so that it does not exceed its maximum capability.

$$
S_{i}<S_{i}^{\max }, i=1, \ldots \ldots, N b r
$$

where $\mathrm{Nbr}$ is the number of transmission lines.

\section{FLOWER POLLINATION ALGORITHM}

Flower Pollination Algorithm is an algorithm developed by Xin-She Yang in 2012 [11]. FPA is a metaheuristic algorithm inspired by natural phenomena related to flower pollination process. Pollination, specific relationships, and the nature of pollinators can be idealized into four rules [12]:

- Biotic and cross-pollination is considered as global pollination process with pollen-carrying pollinators performing Levy flight.

- Abiotic and self-pollination are considered as local pollination.

- Flower constancy can be considered as the reproduction probability is proportional to the similarity of two flowers involved.

- Local and global pollination are controlled with the probability switch $p \in[0,1]$. Because of a physical approach and other factors such as wind, local pollination can have a significant chance (p) in overall activity of pollination.

Two key steps in this algorithm are global pollination and local pollination. At the global pollination step, pollen is carried by pollinators and can move over long distances. This ensures the most optimal pollination and reproduction (best fitness) of the fitness value is represented as $\mathbf{g}^{*}$. The first rule, the specific relationship of interest, mathematically can be represented as follows:

$$
\boldsymbol{x}_{i}^{t+1}=\boldsymbol{x}_{i}^{t}+\mathbf{L} \cdot\left(\boldsymbol{x}_{i}^{t}-\boldsymbol{g}^{*}\right)
$$

where $\boldsymbol{x}_{i}^{t}$ is the $i$-th solution in the $t$-th iteration. Parameter $\boldsymbol{L}$ is the strength of pollination that is obtained from the Levy distribution. 
At the local pollination or second rule, the specific relationship of flowers represented as

$$
x_{i}^{t+1}=x_{i}^{t}+\epsilon\left(x_{j}^{t}-x_{k}^{t}\right)
$$

where $\boldsymbol{x}_{j}^{t}$ and $\boldsymbol{x}_{k}^{t}$ are the current pollen from different flowers of the same plant species, $t$ is represent the current generation (iteration) and $\epsilon$ is random number between 0 and 1 .

Flowchart of FPA method to solve the OPF problems is shown in Fig. 1.

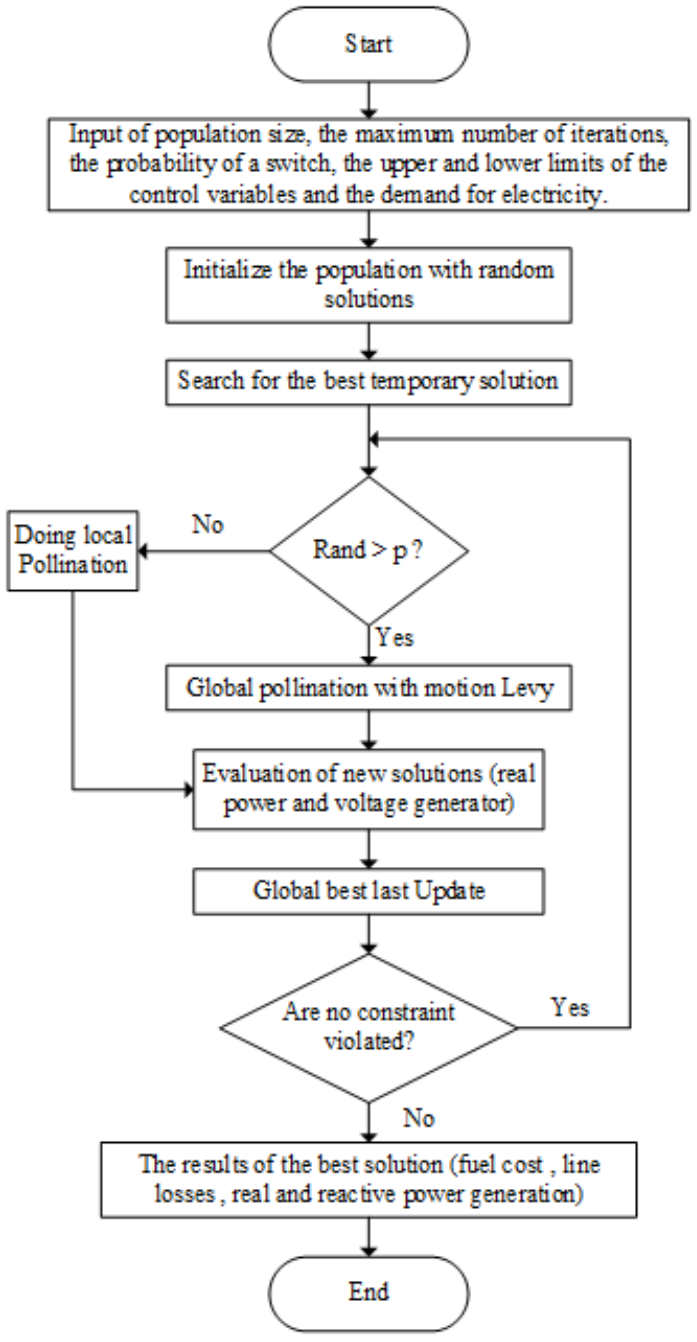

Fig. 1 Flowchart of OPF using FPA.

\section{500 KV JAVA-BALI POWER SYSTEM}

The data of $500 \mathrm{kV}$ Java-Bali power system was obtained from PT. PLN (Persero) which has been used by previous researches [13], [14]. The system has eight generating units which consists of six thermal and two hydro units. Optimization is applied to six thermal generator units, while two units of hydro will operate as its initial condition. The complete electrical system is illustrated in Fig. 2.

Generator data consists of active and reactive power upper and lower limits shown in Table I. Generator fuel function shown in (1) is a form of second order polynomial. The function is obtained from the regression of generation data at different times. The fuel function of the $500 \mathrm{kV}$ Java-Bali system is shown in Appendix 1.

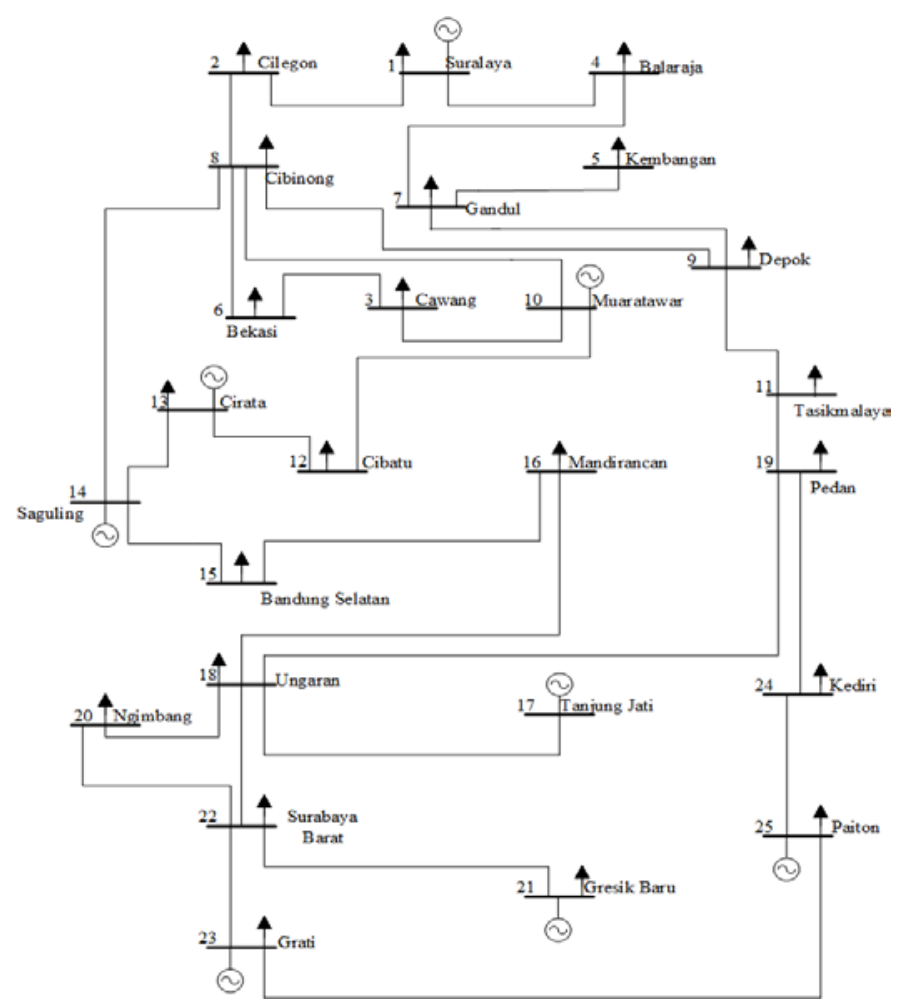

Fig. 2 Single line diagram of 500 kV Java-Bali power System.

TABLE I

POWER LIMIT GENERATOR

\begin{tabular}{|l|l|l|l|l|l|}
\hline No & \multicolumn{1}{|c|}{ Name } & $\begin{array}{c}\text { Pmin } \\
(\mathbf{M W})\end{array}$ & $\begin{array}{c}\text { Pmax } \\
(\mathbf{M W})\end{array}$ & $\begin{array}{c}\text { Qmin } \\
\text { (MVar) }\end{array}$ & $\begin{array}{c}\text { Qmax } \\
\text { (MVar) }\end{array}$ \\
\hline 1. & Suralaya & 1,610 & 4,025 & $-1,478.6$ & $2,494.5$ \\
\hline 2. & Muara Tawar & $1,300.4$ & 3,251 & $-1,859.1$ & $2,438.2$ \\
\hline 3. & Saguling & 280 & 700 & -460.9 & 525 \\
\hline 4. & Cirata & 403.2 & 1,008 & -663.7 & 756 \\
\hline 5. & Tanjung Jati & 1,056 & 2,640 & -969.8 & $1,636.1$ \\
\hline 6. & Gresik Baru & 895.62 & 2,239 & $-1,474.4$ & $1,679.3$ \\
\hline 7. & Grati & 305.8 & 764.5 & -341.3 & 573.4 \\
\hline 8. & Paiton & 1,886 & 4,714 & $-1,750$ & $3,028.3$ \\
\hline
\end{tabular}

The control variable used in this research is active power and magnitude voltage generator. Each generator has a different active power limit. The initial condition of the control variable is shown in Appendix 2. The voltage magnitude limit is at $\pm 5 \%$ of its nominal value. This is in accordance with the rule of Minister of Energy and Mineral Resources of the Republic of Indonesia regarding Grid Code 2007 [15].

In addition to the voltage magnitude, the current constraints that flow through each line are applied to this system. The value of the constraints is related to the technical factors of the lines which has a different maximum current carrying capacity. Using a 1000 MVA base, data network and line current carrying capability are given in Appendix 3. 
TABLE II

RESUltS OF CONTROL VARIABLE USING FPA

\begin{tabular}{|l|l|l|l|l|}
\hline \multirow{2}{*}{ No } & \multirow{2}{*}{$\begin{array}{l}\text { Control } \\
\text { variable }\end{array}$} & \multicolumn{2}{|c|}{ Limitation } & \multirow{2}{*}{ Result } \\
\cline { 3 - 4 } & Minimal & Maximal & \\
\hline 1 & P1 (MW) & 1,610 & 4,025 & $1,912.87$ \\
\hline 2 & P10(MW) & $1,300.4$ & 3,251 & $1,400.40$ \\
\hline 3 & P13(MW) & 280 & 700 & 594 \\
\hline 4 & P14(MW) & 403.2 & 1,008 & 662 \\
\hline 5 & P17(MW) & 1,056 & 2,640 & $1,856.05$ \\
\hline 6 & P21(MW) & 895.62 & 2,239 & 895.2 \\
\hline 7 & P23(MW) & 305.8 & 764.5 & 305.80 \\
\hline 8 & P25(MW) & 1,886 & 4,714 & 4,714 \\
\hline 9 & V1 (p.u) & 0.95 & 1.05 & 1.050 \\
\hline 10 & V10(p.u) & 0.95 & 1.05 & 1.047 \\
\hline 11 & V13(p.u) & 0.95 & 1.05 & 1.050 \\
\hline 12 & V14(p.u) & 0.95 & 1.05 & 1.037 \\
\hline 13 & V17(p.u) & 0.95 & 1.05 & 1.050 \\
\hline 14 & V21(p.u) & 0.95 & 1.05 & 1.050 \\
\hline 15 & V23(p.u) & 0.95 & 1.05 & 1.049 \\
\hline 16 & V25(p.u) & 0.95 & 1.05 & 1.050 \\
\hline
\end{tabular}

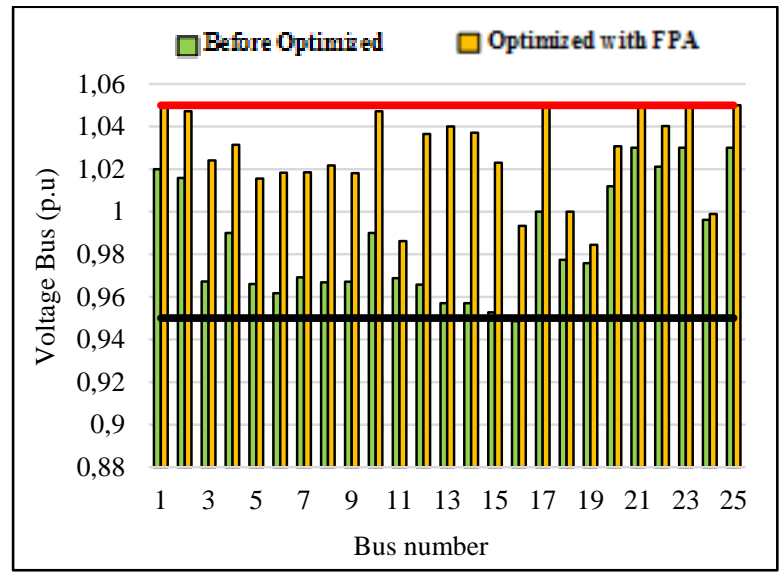

Fig. 3 Comparison of the voltage profile.

Active and reactive power data on each bus is required to perform a power flow analysis. In this study, data of power that occurs during peak loads are shown in Appendix 4.

\section{Results AND ANALYsis}

This research was conducted with FPA parameters in which the probability switch value is set at 0.8 , population size 20 and number of iterations of 6,000, with tolerance of 0.001 . The results are shown in Table II. From these results, note that the value of control variables are still in the normal range.

The voltage magnitude on all buses after optimization is in the range of 0.95 p.u - 1.1 p.u. The lowest voltage value is 0.984 p.u on bus 19 , while the highest voltage of 1.05 p.u are on buses $1,17,21$, and 25 . However, the value is still within the allowable range. Comparison of voltage between before and after optimization using FPA is shown in Fig. 3.

In addition to voltage constraints, line current is also a constraint that should not be violated. The current passing through the line must not exceed its current carrying capacity. Of all lines, current through the line is still within safe limits.
The smallest percentage of flowing current is $4.01 \%$, which occurs on line number 11 . The largest percentage of line flow occurs on line number 16 of $52.06 \%$. The comparisons of percentage of the line current between before and after optimization using FPA is shown in Fig. 4.

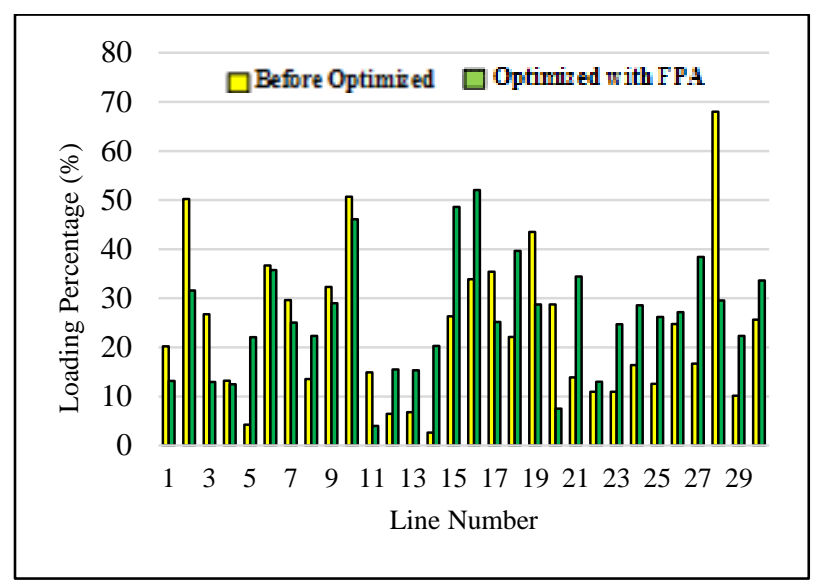

Fig. 4 Comparison of power flow line.

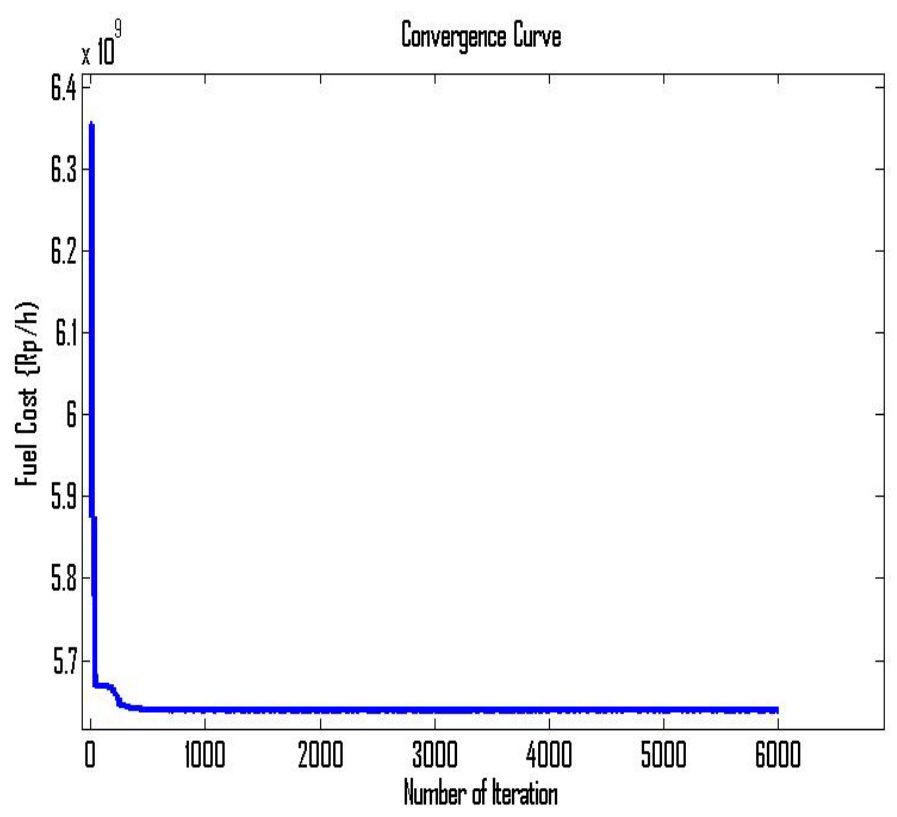

Fig. 5 Convergence curve of FPA.

Convergence in a process of optimization that is important to note and show how the value of objective function reaches the most optimal results. After a certain point, the value will be relatively constant with no significant changes. Fig. 5 shows the convergence graph of total generating costs by the FPA method. Based on the picture, it can be seen that fuel cost function reaches its convergence at the 1000th iteration.

The results of FPA method show a satisfactory performance. FPA method is able to decrease the fuel cost from Rp6,492,201,738/hour to Rp5,638,693,790/hour. This means that fuel costs are reduced by Rp853,507,948/hour (13.15\%). Comparison of active power generation, as well as fuel costs before and after optimization are shown in Table III. 
TABLE III

COMPARISON OF MiNIMIZATION OBJECTIVE FUNCTION

\begin{tabular}{|l|l|l|l|l|}
\hline \multirow{2}{*}{ Generator } & \multicolumn{2}{|c|}{ Data Operation PLN } & \multicolumn{2}{c|}{ FPA } \\
\cline { 2 - 5 } & \multicolumn{1}{|c|}{$\begin{array}{c}\text { Power } \\
\text { (MW) }\end{array}$} & $\begin{array}{c}\text { Cost } \\
\text { (x1000 } \\
\text { Rp/hour) }\end{array}$ & $\begin{array}{c}\text { Power } \\
\text { (MW) }\end{array}$ & $\begin{array}{c}\text { Cost } \\
\text { (x1000 } \\
\text { Rp/hour) }\end{array}$ \\
\hline Suralaya & $2,814.48$ & $1,131,383$ & 1912,87 & 798,596 \\
\hline Muaratawar & 1,785 & $1,794,021$ & 1400,4 & $1,427,640$ \\
\hline Cirata & 594 & - & 594 & - \\
\hline Saguling & 662 & - & 662 & - \\
\hline Tanjungjati & 1,971 & 633,534 & 1856,049 & 595,260 \\
\hline Gresik & 1,371 & $1,226,721$ & 895,62 & 828,402 \\
\hline Grati & 441 & 732,309 & 305,8 & 565,841 \\
\hline Paiton & 2,572 & 972,845 & 4714 & $1,422,953$ \\
\hline Total & $12,210.48$ & $6,492,202$ & $12,340.74$ & $5,638,694$ \\
\hline \multicolumn{2}{|l|}{ Reduction of costs (x1000 Rp/hour) } & 853,508 \\
\hline
\end{tabular}

\section{CONCLUSION}

In this study, the FPA method was used to solve OPF problem of $500 \mathrm{kV}$ Java-Bali power system in Indonesia. The system consists of 25 buses with 30 branches and eight generator units. Active power and magnitude voltage optimization are performed on six thermal power plants. The results showed satisfactory performance of FPA method. The proposed method can lower the fuel cost from Rp 6,492,201,738/hour to Rp 5,638,693,790/hour or by $13.15 \%$ without violating any constraints.

\section{ACKNOWLEDGMENT}

The authors are thankful to the management of Department of Electrical Engineering \& Information Technology Universitas Gadjah Mada for providing facilities and publishing this research.

\section{REFERENCES}

[1] PT. PLN (Persero), "Catalogue in Publication PLN Statistics 2015." PT.PLN (Persero), ISSN : 0852-8179, 2016.

[2] H. Saadat, Power System Analysis. New York: WCB McGraw-Hil, 1998.

[3] J. Yuryevich and K. P. Wong, "Evolutionary Programming Based Optimal Power Flow Algorithm,” IEEE Trans. Power Syst., vol. 14, no. 4, pp. 1245-1250, 1999.

[4] A. A. Abou El Ela, M. A. Abido, and S. R. Spea, "Optimal Power Flow Using Differential Evolution Algorithm,” Electr. Power Syst. Res., vol. 80, no. 7, pp. 878-885, 2010.

[5] I. Oumarou, P. D. Jiang, and P. C. Yijia, "Particle Swarm Optimization Applied to Optimal Power Flow Solution," Fifth International Conference on Natural Computation, 2009.

[6] M. S. Osman, M. A. Abo-Sinna, and A. A. Mousa, "A Solution to the Optimal Power Flow Using Genetic Algorithm,” Appl. Math. Comput., vol. 155, no. 2, pp. 391-405, 2004.

[7] B. S. Kumar, M. Suryakalavathi, and G. V. N. Kumar, "Optimal Power Flow With Static VAR Compensator Based on Flower Pollination Algorithm to Minimize Real Power Losses," Conf. Power, Control. Commun. Comput. Technol. Sustain. Growth, PCCCTSG 2015, no. 2, pp. 112-116, 2016.

[8] D. L. Pravallika and B. V. Rao, "Flower Pollination Algorithm Based Optimal Setting of TCSC to Minimize the Transmission Line Losses in the Power System,” Procedia Comput. Sci., vol. 92, pp. 30-35, 2016.

[9] J. A. Regalado, E. B. E, and E. Cuevas, "Optimal Power Flow Solution Using Modified Flower Pollination Algorithm," IEEE Int. Autumn Meet. Power, Electron. Comput., 2015.
[10] B. Mahdad and K. Srairi, "Security Constrained Optimal Power Flow Solution Using New Adaptive Partitioning Flower Pollination Algorithm,” Appl. Soft Comput., vol. 46, pp. 501-522, 2016.

[11] X.-S. Yang, "Flower Pollination Algorithm for Global Optimization," Unconv. Comput. Nat. Comput. 2012, Lect. Notes Comput. Sci., vol. 7445, pp. 240-249, 2012.

[12] X. S. Yang, M. Karamanoglu, and X. He, "Multi-objective Flower Algorithm for Optimization,” Procedia Comput. Sci., vol. 18, no. JUNE, pp. 861-868, 2013.

[13] Yassir, Sarjiya, and T. Haryono, "Algoritma Genetika Sebagai Solusi Optimal Power Flow Pada Sistem Kelistrikan 500 kV Jawa Bali," Transmisi, vol. 15, no. 2, pp. 107-113, 2013.

[14] Taqiyuddin, Sarjiya, and S. P. Hadi, "Studi Optimal Power Flow pada Sistem Kelistrikan 500 kV Jawa-Bali dengan Menggunakan Particle Swarm Optimization ( PSO ),” JNTETI, vol. 2, no. 3, 2013.

[15] Regulation of the Minister of Energy and Mineral Resources of the Republic of Indonesia Number 3 Year 2007, 2007.

\section{APPENDIX}

Appendix 1. Fuel Cost Coefficients of 500 kV Java Bali System

\begin{tabular}{|l|l|c|l|l|}
\hline \multirow{2}{*}{$\begin{array}{l}\text { No. } \\
\text { Bus }\end{array}$} & \multirow{2}{*}{ Generator } & \multicolumn{3}{|c|}{ Fuel cost function coefficients } \\
\cline { 3 - 5 } & & \multicolumn{1}{c|}{$\boldsymbol{\alpha}$} & \multicolumn{1}{c|}{$\boldsymbol{\beta}$} & \multicolumn{1}{c|}{$\boldsymbol{\gamma}$} \\
\hline 1 & Suralaya & $47,071,299.8$ & $407,989.965$ & -7.90 \\
\hline 10 & Muaratawar & $-196,885,587.4$ & $1,322,770.659$ & -116.23 \\
\hline 17 & Tanjungjati & $104,589,684.8$ & $199,772.387$ & 34.75 \\
\hline 21 & Gresik & $81,256,913.02$ & $831,821.003$ & 2.68 \\
\hline 23 & Grati & $198,252,082.2$ & $1,176,938.992$ & 75.30 \\
\hline 25 & Paiton & $5,575,248.3$ & $466,630.8$ & -35.21 \\
\hline
\end{tabular}

Appendix 2. Limit of Control Variable

\begin{tabular}{|l|l|l|l|l|}
\hline \multirow{2}{*}{ No. } & \multirow{2}{*}{$\begin{array}{l}\text { Control } \\
\text { Variable }\end{array}$} & \multicolumn{2}{|c|}{ Limitation } & \multirow{2}{*}{ Initial } \\
\cline { 3 - 4 } & Minimal & Maximal & \\
\hline 1 & P1 (MW) & 1,610 & 4,025 & 2,735 \\
\hline 2 & P10(MW) & $1,300.4$ & 3,251 & 1,785 \\
\hline 3 & P13(MW) & 280 & 700 & 594 \\
\hline 4 & P14(MW) & 403.2 & 1,008 & 662 \\
\hline 5 & P17(MW) & 1,056 & 2,640 & 1,971 \\
\hline 6 & P21(MW) & 895.62 & 2,239 & 1,371 \\
\hline 7 & P23(MW) & 305.8 & 764.5 & 441 \\
\hline 8 & P25(MW) & 1,886 & 4,714 & 2,572 \\
\hline 9 & V1 (p.u) & 0.95 & 1.05 & 1.020 \\
\hline 10 & V10(p.u) & 0.95 & 1.05 & 0.990 \\
\hline 11 & V13(p.u) & 0.95 & 1.05 & 0.957 \\
\hline 12 & V14(p.u) & 0.95 & 1.05 & 0.957 \\
\hline 13 & V17(p.u) & 0.95 & 1.05 & 1.000 \\
\hline 14 & V21(p.u) & 0.95 & 1.05 & 1.030 \\
\hline 15 & V23(p.u) & 0.95 & 1.05 & 1.030 \\
\hline 16 & V25(p.u) & 0.95 & 1.05 & 1.030 \\
\hline
\end{tabular}

Appendix 3. Branch Data of 500 kV Java Bali System

\begin{tabular}{|l|l|l|c|c|l|l|}
\hline No. & $\begin{array}{c}\text { From } \\
\text { Bus }\end{array}$ & $\begin{array}{c}\text { To } \\
\text { Bus }\end{array}$ & $\begin{array}{c}\mathbf{R} \\
(\mathbf{p . u})\end{array}$ & $\begin{array}{c}\mathbf{X} \\
(\mathbf{p . u})\end{array}$ & $\begin{array}{c}\mathbf{B} / \mathbf{2} \\
\mathbf{( p . u )}\end{array}$ & $\begin{array}{c}\text { Current } \\
\text { Limit } \\
(\mathbf{A})\end{array}$ \\
\hline 1. & 1 & 2 & 0.001 & 0.007 & 0 & 4,800 \\
\hline 2. & 1 & 4 & 0.004 & 0.035 & 0 & 3,960 \\
\hline 3. & 2 & 8 & 0.013 & 0.147 & 0.004 & 2,400 \\
\hline 4. & 5 & 7 & 0.002 & 0.017 & 0 & 4,800 \\
\hline 5. & 7 & 9 & 0.001 & 0.007 & 0 & 3,960 \\
\hline
\end{tabular}




\begin{tabular}{|l|l|l|l|l|l|l|}
\hline No. & $\begin{array}{c}\text { From } \\
\text { Bus }\end{array}$ & $\begin{array}{c}\text { To } \\
\text { Bus }\end{array}$ & $\begin{array}{c}\mathbf{R} \\
\mathbf{( p . u )}\end{array}$ & $\begin{array}{c}\mathbf{X} \\
\mathbf{( p . u )}\end{array}$ & $\begin{array}{c}\text { B/2 } \\
\mathbf{( p . u )}\end{array}$ & $\begin{array}{c}\text { Current } \\
\text { Limit } \\
\mathbf{( A )}\end{array}$ \\
\hline 6. & 8 & 6 & 0.004 & 0.043 & 0 & 1,980 \\
\hline 7. & 8 & 10 & 0.006 & 0.060 & 0 & 1,980 \\
\hline 8. & 8 & 14 & 0.004 & 0.046 & 0.004 & 4,800 \\
\hline 9. & 3 & 6 & 0.002 & 0.019 & 0 & 1,980 \\
\hline 10. & 3 & 10 & 0.006 & 0.054 & 0 & 1,980 \\
\hline 11. & 10 & 12 & 0.003 & 0.027 & 0 & 3,960 \\
\hline 12. & 12 & 13 & 0.003 & 0.026 & 0 & 3,960 \\
\hline 13. & 13 & 14 & 0.001 & 0.014 & 0 & 3,960 \\
\hline 14. & 14 & 15 & 0.002 & 0.022 & 0 & 4,800 \\
\hline 15. & 15 & 16 & 0.007 & 0.067 & 0.006 & 3,960 \\
\hline 16. & 16 & 18 & 0.013 & 0.129 & 0.012 & 3,960 \\
\hline 17. & 18 & 17 & 0.014 & 0.151 & 0.004 & 4,800 \\
\hline 18. & 18 & 22 & 0.016 & 0.152 & 0.004 & 1,980 \\
\hline 19. & 18 & 19 & 0.009 & 0.087 & 0 & 1,980 \\
\hline 20. & 22 & 21 & 0.001 & 0.013 & 0 & 3,960 \\
\hline 21. & 22 & 23 & 0.004 & 0.045 & 0 & 4,800 \\
\hline 22. & 9 & 8 & 0.001 & 0.008 & 0 & 3,960 \\
\hline 23. & 9 & 11 & 0.014 & 0.157 & 0.015 & 4,800 \\
\hline 24. & 11 & 19 & 0.015 & 0.171 & 0.016 & 4,800 \\
\hline 25. & 19 & 24 & 0.010 & 0.115 & 0.011 & 4,800 \\
\hline 26. & 24 & 25 & 0.010 & 0.115 & 0.011 & 4,800 \\
\hline 27. & 25 & 23 & 0.004 & 0.050 & 0.005 & 4,800 \\
\hline 28. & 4 & 7 & 0.003 & 0.029 & 0 & 1,980 \\
\hline 29. & 20 & 18 & 0.023 & 0.226 & 0.101 & 1,980 \\
\hline 30. & 20 & 22 & 0.006 & 0.057 & 0 & 1,980 \\
\hline
\end{tabular}

Appendix 4. Bus Data of 500 kV Java Bali System

\begin{tabular}{|l|l|l|l|l|l|}
\hline \multirow{2}{*}{$\begin{array}{l}\text { No. } \\
\text { bus }\end{array}$} & \multirow{2}{*}{ Type } & \multicolumn{2}{|c|}{ Generation } & \multicolumn{2}{c|}{ Load } \\
\cline { 3 - 6 } & & MW & MVar & \multicolumn{1}{c|}{ MW } & MVar \\
\hline 1 & Swing & 2,735 & 1,254 & 201 & 98 \\
\hline 2 & Load & - & - & 293 & 221 \\
\hline 3 & Load & - & - & 322 & 75 \\
\hline 4 & Load & - & - & 624 & -14 \\
\hline 5 & Load & - & - & 522 & 125 \\
\hline 6 & Load & - & - & 1,118 & 264 \\
\hline 7 & Load & - & - & 761 & 132 \\
\hline 8 & Load & - & - & 616 & 330 \\
\hline 9 & Load & - & - & 641 & 204 \\
\hline 10 & Gen. & 1,785 & 859 & - & - \\
\hline 11 & Load & - & - & 219 & 83 \\
\hline 12 & Load & - & - & 688 & 467 \\
\hline 13 & Gen. & 594 & 209 & 586 & 232 \\
\hline 14 & Gen. & 662 & 125 & - & - \\
\hline 15 & Load & - & - & 733 & 426 \\
\hline 16 & Load & - & - & 309 & 131 \\
\hline 17 & Gen. & 1,971 & 58 & 238 & 11 \\
\hline 18 & Load & - & - & 417 & 468 \\
\hline 19 & Load & - & - & 608 & 229 \\
\hline 20 & Load & - & - & 302 & 70 \\
\hline 21 & Gen. & 1,371 & 286 & 174 & 64 \\
\hline 22 & Load & - & - & 899 & 512 \\
\hline 23 & Gen. & 441 & 58 & 510 & 191 \\
\hline 24 & Load & - & - & 627 & 188 \\
\hline 25 & Gen. & 2,572 & 611 & 650 & 146 \\
\hline Total & & 12,131 & 3,460 & 12,058 & 4,650 \\
\hline & & & & & \\
\hline
\end{tabular}

